\title{
MicroRNA-494 suppresses hypoxia/reoxygenation-induced cardiomyocyte apoptosis and autophagy via the PI3K/AKT/mTOR signaling pathway by targeting SIRT1
}

\author{
SHUWEI NING ${ }^{1}$, ZHIYING LI ${ }^{1}$, ZHENYU JI ${ }^{2}$, DANDAN FAN ${ }^{2}$, KEKE WANG ${ }^{1}$, QIAN WANG ${ }^{1}$, \\ LEI HUA ${ }^{1}$, JUNYUE ZHANG $^{1}$, XIANGGUANG MENG ${ }^{1}$ and YIQIANG YUAN ${ }^{3}$ \\ ${ }^{1}$ Laboratory of Cardiovascular Disease and Drug Research, Zhengzhou No. 7 People's Hospital, Zhengzhou, Henan 450016; \\ ${ }^{2}$ Institute of Medical and Pharmaceutical Sciences, Zhengzhou University, Zhengzhou, Henan 450052; \\ ${ }^{3}$ Department of Cardiovascular Internal Medicine, Henan Provincial Chest Hospital, Zhengzhou, Henan 450003, P.R. China
}

Received May 7, 2020; Accepted October 2, 2020

DOI: $10.3892 / \mathrm{mmr} .2020 .11636$

\begin{abstract}
Acute myocardial infarction can be caused by ischemia/reperfusion (I/R) injury; however, the mechanism underlying $\mathrm{I} / \mathrm{R}$ is not completely understood. The present study investigated the functions and mechanisms underlying microRNA (miR)-494 in I/R-induced cardiomyocyte apoptosis and autophagy. Hypoxia/reoxygenation (H/R)-treated H9c2 rat myocardial cells were used as an in vitro $\mathrm{I} / \mathrm{R}$ injury model. Apoptosis and autophagy were analyzed by Cell Counting Kit- 8 assay, Lactic dehydrogenase and superoxide dismutase assay, flow cytometry, TUNEL staining and western blotting. Reverse transcription-quantitative PCR demonstrated that, $\mathrm{H} 9 \mathrm{c} 2$ cells treated with $12 \mathrm{~h}$ hypoxia and $3 \mathrm{~h}$ reoxygenation displayed significantly downregulated miR-494 expression levels compared with control cells. Compared with the corresponding negative control (NC) groups, miR-494 mimic reduced H/R-induced cell apoptosis and autophagy, whereas miR-494 inhibitor displayed the opposite effects. Silent information regulator 1 (SIRT1) was identified as a target gene of
\end{abstract}

Correspondence to: Dr Xiangguang Meng, Laboratory of Cardiovascular Disease and Drug Research, Zhengzhou No. 7 People's Hospital, 17 Jingnan 5th Road, Zhengzhou, Henan 450016, P.R. China E-mail: mengxiangguang2015@163.com

Professor Yiqiang Yuan, Department of Cardiovascular Internal Medicine, Henan Provincial Chest Hospital, 1 Weiwu Road, Zhengzhou, Henan 450003, P.R. China

E-mail: yiqiang2019@126.com

Abbreviations: I/R, ischemia/reperfusion; miR-494, microRNA-494; $\mathrm{H} / \mathrm{R}$, hypoxia/reoxygenation; SIRT1, silent information regulator 1 ; IHD, ischemic heart disease; miRs, microRNAs; siSIRT1, small interfering RNA targeting SIRT1; NC, negative control; RT-qPCR, reverse transcription-quantitative PCR; CCK-8, Cell Counting Kit-8; LDH, lactic dehydrogenase; SOD, superoxide dismutase; WT, wild-type; MUT, mutant

Key words: miR-494, myocardial I/R injury, SIRT1, apoptosis, autophagy, PI3K/AKT/mTOR signaling pathway
miR-494. Furthermore, miR-494 inhibitor-mediated effects on H/R-induced cardiomyocyte apoptosis and autophagy were partially reversed by SIRT1 knockdown. Moreover, compared with si-NC, SIRT1 knockdown significantly increased the phosphorylation levels of PI3K, AKT and mTOR in H/R-treated and miR-494 inhibitor-transfected H9c2 cells. Collectively, the results indicated that miR-494 served a protective role against H/R-induced cardiomyocyte apoptosis and autophagy by directly targeting SIRT1, suggesting that miR-494 may serve as a novel therapeutic target for myocardial I/R injury.

\section{Introduction}

Ischemic heart disease (IHD) can cause congestive heart failure and myocardial infarction (1). Among the treatment strategies available for IHD, timely reperfusion of the occluded artery, such as coronary bypass surgery, coronary angioplasty and thrombolysis, is beneficial and can treat a wide range of myocardial injuries (2). However, reperfusion can also result in another myocardial ischemia/reperfusion (I/R) injury (3), which can induce cardiomyocyte death and remodeling, and result in irreversible myocardial damage (4).

Cell apoptosis is a major morphologically distinctive feature of programmed cell death, which is crucial to numerous biological processes such as tumorigenesis, differentiation, immunity, inflammation and cell growth (5). Autophagy participates in degrading damaged cytoplasmic proteins and senescent organelles via the lysosomal pathway (6). However, there are complex interactions between apoptosis and autophagy (7). Increasing evidence has demonstrated that apoptosis and autophagy, which are two major pathophysiological processes, serve a role in the pathogenesis of myocardial I/R injury $(8,9)$. However, the detailed mechanisms underlying myocardial I/R injury are not completely understood. Therefore, investigating the regulation of apoptosis and autophagy may aid with the development of beneficial treatment strategies for myocardial I/R injury.

MicroRNAs (miRNAs/miRs) are small endogenous non-coding RNAs, 22-25 nucleotides in length, which can bind to the target mRNA at the 3'-untranslated region (3'-UTR) to 
regulate gene expression (10). miRs serve a significant role in a number of human cardiovascular diseases, including myocardial I/R injury, such as miR-21, which serves a protective role in myocardial I/R injury $(11,12)$. Moreover, miRs are involved in the regulation of apoptosis, autophagy, proliferation, differentiation and other biological processes (13). Previous studies have identified numerous miRs as critical regulators of myocardial I/R injury. For example, miR-496 overexpression can protect myocardial cells from apoptosis following hypoxia/reoxygenation $(\mathrm{H} / \mathrm{R})$ treatment and promote cell proliferation (14). Moreover, miR-374a-5p displays a protective effect on cardiac $\mathrm{I} / \mathrm{R}$ injury in vitro and in vivo (15), and miR-24-3p also displays cardioprotective effects in myocardial I/R injury (16). Increasing evidence has suggested that miR-494 serves a pivotal role in cell apoptosis, proliferation, tumorigenesis, metastasis and other processes (17). Zhai et al (18) investigated the expressional differences of miR-494 in rats with cerebral I/R injury. miR-494 upregulation inhibited human hepatocyte L02 cell apoptosis following hypoxia/ischemia induction via activating the PI3K/AKT signaling pathway (19). Wang et al (20) reported that miR-494 was involved in I/R-induced myocardium injury in vivo. However, to the best of our knowledge, the role of miR-494 in H/R-induced cardiomyocyte apoptosis and autophagy has not been previously reported.

In previous years, as a nicotinamide adenine dinucleotide-dependent histone deacetylation enzyme, silent information regulator 1 (SIRT1) has become the focus of numerous studies $(21,22)$. SIRT1 can resist oxidative stress, inhibit apoptosis and alleviate inflammatory reaction (23-25). Moreover, Liu et al (26) demonstrated that pancreatic cancer chemoresistance, invasion and proliferation could be inhibited by miR-494 via SIRT1. Li et al (27) reported that SIRT1 was a key factor in regulating gastric cancer cell autophagy via the $\mathrm{PI} 3 \mathrm{~K} / \mathrm{AKT} / \mathrm{mTOR}$ signaling pathway. Increasing evidence has also indicated that SIRT1 serves as a mediator for myocardial I/R injury (28). However, the effects of miR-494 and SIRT1 on myocardial I/R injury and their association with apoptosis and autophagy require further investigation.

The present study used rat-derived $\mathrm{H} 9 \mathrm{c} 2$ cells to establish an in vitro $\mathrm{H} / \mathrm{R}$ myocardial cell model to simulate myocardial I/R injury. Subsequently, the functions and mechanisms underlying miR-494 in H9c2 cell apoptosis and autophagy following $\mathrm{H} / \mathrm{R}$ were investigated.

\section{Materials and methods}

Cell culture and H/R treatment. H9c2 cells (Procell Life Science \& Technology Co., Ltd.) were maintained in DMEM (Beijing Solarbio Science \& Technology Co., Ltd.) supplemented with $100 \mathrm{mg} / \mathrm{ml}$ streptomycin, $100 \mathrm{U} / \mathrm{ml}$ penicillin, and 10\% FBS (Gibco; Thermo Fisher Scientific, Inc.) at $37^{\circ} \mathrm{C}$ with $5 \% \mathrm{CO}_{2}$. Mycoplasma contamination in cell substrates was detected to confirm the availability of cells. For control treatment, cells were cultured in DMEM with $5 \% \mathrm{CO}_{2}$ for $12 \mathrm{~h}$. For $\mathrm{H} / \mathrm{R}$ treatment, $\mathrm{H} 9 \mathrm{c} 2$ cells were cultured in glucose- and serum-free DMEM in a $94 \% \mathrm{~N}_{2}, 5 \% \mathrm{CO}_{2}$ and $1 \% \mathrm{O}_{2}$ atmosphere for $12 \mathrm{~h}$ at $37^{\circ} \mathrm{C}$ to simulate hypoxia. Subsequently, the medium was replaced with DMEM supplemented with $10 \%$ FBS in a $95 \%$ air and $5 \% \mathrm{CO}_{2}$ atmosphere for $3 \mathrm{~h}$ at $37^{\circ} \mathrm{C}$ to simulate reoxygenation.
Cell transfection. $\mathrm{H} 9 \mathrm{c} 2$ cells were seeded into 6-well plates $\left(3.5 \times 10^{5}\right.$ cells/well $)$ or 96 -well plates $\left(1.5 \times 10^{4}\right.$ cells/well $)$. At $80 \%$ confluence, cells were transfected with $50 \mathrm{nM}$ miR-494 mimic (5'-UGAAACAUACACGGGAAACCUCU-3'), $50 \mathrm{nM}$ miR-494 mimic negative control (NC; 5'-UUCUCCGAACGU GUCACGUTT-3'), 100 nM miR-494 inhibitor (5'-AGAGGUUU CCCGUGUAUGUUUCA-3'), 100 nM miR-494 inhibitor NC (5'-CAGUACUUUUGUGUAGUACAA-3'), $50 \mathrm{nM}$ small interfering (si)RNA targeting SIRT1 (siSIRT1; 5'-CCCUGUAAA GCUUUCAGAATT-3') or $50 \mathrm{nM}$ siRNA negative control (5'-UUCUCCGAACGUGUCACGUTT-3' for $4 \mathrm{~h}$ at $37^{\circ} \mathrm{C}$; all purchased from Shanghai GenePharma Co., Ltd.) using Lipofectamine $^{\circledR} 2000$ (Invitrogen; Thermo Fisher Scientific, Inc.). At $28 \mathrm{~h}$ post-transfection, cells were collected, exposed to $\mathrm{H} / \mathrm{R}$ treatment and used for subsequent experiments.

$R N A$ extraction and reverse transcription-quantitative $P C R(R T-q P C R)$. Total RNA was isolated from $\mathrm{H} 9 \mathrm{c} 2$ cells using TRIzol $^{\circledR}$ (Invitrogen; Thermo Fisher Scientific, Inc.). RNA quality and concentration were detected using an ultraviolet spectrophotometer. Total RNA was reverse transcribed into cDNA using a Transcriptor cDNA Synthesis kit (Roche Applied Science). The reverse transcription reactions were incubated for $40 \mathrm{~min}$ at $37^{\circ} \mathrm{C}$ and $5 \mathrm{~min}$ at $85^{\circ} \mathrm{C}$. Subsequently, qPCR was performed using SYBR Premix Ex Taq (Takara Bio, Inc.) on a StepOnePlus Realtime PCR system (Applied Biosystems; Thermo Fisher Scientific, Inc.). The following thermocycling conditions were used for qPCR: $95^{\circ} \mathrm{C}$ for $30 \mathrm{sec}$; followed by 42 cycles of $95^{\circ} \mathrm{C}$ for $5 \mathrm{sec}$ and $55^{\circ} \mathrm{C}$ for $35 \mathrm{sec}$. The following primers were used for qPCR: miR-494 forward, 5'-CGCTGA AACATACACGGGAA-3' and reverse, 5'-CAGTGCAGGGTC CGAGGTAT-3'; U6 forward, 5'-CTCGCTTCGGCAGCACA-3' and reverse, 5'-AACGCTTCACGAATTTGCGT-3'; SIRT1 forward, 5'-CTCCTCATTGTTATTGGGTCTTCTC-3' and reverse, 5'-ACTCGCCACCTAACCTATGACAC-3'; and GAPDH forward, 5'-AGATCCCGCTAACATCAAATGG-3' and reverse, 5'-GTTCACACCCATCACAAACATG-3'. miRNA and mRNA expression levels were quantified using the $2^{-\Delta \Delta C \mathrm{C}}$ method (29) and normalized to the internal reference genes U6 and GAPDH, respectively.

Cell Counting Kit-8 (CCK-8) assay. H9c2 cells $\left(1 \times 10^{6}\right.$ cells/well) were incubated with $10 \mu \mathrm{lCCK}-8$ reagent (Dojindo Molecular Technologies, Inc.) for $1 \mathrm{~h}$ at $37^{\circ} \mathrm{C}$. Absorbance was measured at a wavelength of $450 \mathrm{~nm}$ using a microplate reader. Subsequently, cell viability was calculated. Cell viability (\%) $=(\mathrm{OD}$ control group $-\mathrm{OD}$ treatment group $) / \mathrm{OD}$ control group $\times 100 \%$

Lactic dehydrogenase ( $\mathrm{LDH}$ ) and superoxide dismutase (SOD) levels detection. To detect the release and activity of two specific marker enzymes, LDH (cat. no. CK12) and SOD commercial kits (cat. no. S311; both Dojindo Molecular Technologies, Inc.) were used according to the manufacturer's protocol. Absorbance was measured at a wavelength of $490 \mathrm{~nm}$ $(\mathrm{LDH})$ or $450 \mathrm{~nm}$ (SOD) using a microplate reader.

Early and late apoptosis detection via flow cytometry. $\mathrm{H} 9 \mathrm{c} 2$ cells were harvested with $0.25 \%$ trypsin and washed with PBS. Following staining with $5 \mu 1$ 7-Amino-Actinomycin D and 
$5 \mu 1 \mathrm{PE}$ Annexin V (cat. no. BD 559763; BD Biosciences) for $18 \mathrm{~min}$ in the dark at $37^{\circ} \mathrm{C}$, early and late apoptosis was examined using a FACSMelody flow cytometer (BD Biosciences) with FlowJo software (version 7.6.1; FlowJollc).

TdT-mediated dUTP-biotin nick end-labeling (TUNEL) staining. H9c2 cells were fixed for $30 \mathrm{~min}$ in $4 \%$ paraformaldehyde at $37^{\circ} \mathrm{C}$. Following washing three times with PBS and permeabilization with $0.1 \%$ Triton $\mathrm{X}-100$ for $15 \mathrm{~min}$ at $37^{\circ} \mathrm{C}$, cells were stained with $50 \mu 1$ TUNEL mix (Roche Diagnostics) for $1 \mathrm{~h}$ at room temperature. Subsequently, nuclei were labeled by incubating cells with $5 \mu \mathrm{g} / \mathrm{ml}$ DAPI (Sigma-Aldrich; Merck KGaA) for $8 \mathrm{~min}$ in the dark. Following three washes with PBS, TUNEL-positive apoptotic cells were observed in five randomly selected fields of views using a fluorescent microscope (Olympus Corporation; magnification, x200).

Western blotting. Total protein was extracted from H9c2 cells using RIPA buffer (Invitrogen; Thermo Fisher Scientific, Inc.). Bicinchoninic Acid Protein Assay kit (Thermo Fisher Scientific, Inc.) was used to measure protein concentration. Equal amounts of protein lysates (30 $\mu \mathrm{g} /$ lane) were separated via $10 \%$ SDS-PAGE and transferred to PVDF membranes. Following blocking with $5 \%$ skim milk for $1 \mathrm{~h}$ at $37^{\circ} \mathrm{C}$, the membranes were incubated overnight at $4^{\circ} \mathrm{C}$ with primary antibodies targeted against: Bcl-2 (cat. no. ab196495; 1:1,000; Abcam), Bax (cat. no. ab32503; 1:5,000; Abcam), microtubule-associated proteins 1A/1B light chain 3 b2 (LC3B; cat. no. ab192890; 1:2,000; Abcam), SIRT1 (cat. no. ab189494; 1:1,000; Abcam), p62 (cat. no. ab109012; 1:8,000; Abcam), Beclin-1 (cat. no. ab207612; 1:2,000; Abcam), phosphorylated (p)-PI3K (cat. no. ab182651; 1:5,000; Abcam), p-AKT (cat. no. ab81283; 1:3,000; Abcam), p-mTOR (cat. no. ab137133; 1:1,000; Abcam), PI3K (cat. no. ab140307; 1:2,000; Abcam), AKT (cat. no. ab179463; 1:5,000; Abcam), mTOR (cat. no. ab2732; 1:2,000; Abcam) and GAPDH (cat. no. ab181602; $1: 8,000$; Abcam). Following washing, the membranes were incubated with a horseradish peroxidase-conjugated goat anti-rabbit IgG secondary antibody (cat. no. ab6721; $1: 2,000$; Abcam) or a horseradish peroxidase-conjugated goat anti-mouse IgG secondary antibody (cat. no. ab6728; 1:2,000; Abcam) at room temperature for $2.5 \mathrm{~h}$. Protein bands were visualized using enhanced chemiluminescence detection methods (Clarity; Bio-Rad Laboratories, Inc.). Protein expression levels were semi-quantified using ImageJ software (version 4.62; National Institutes of Health) with GAPDH as the loading control.

Dual-luciferase reporter assay. TargetScan (version 7.2; www. targetscan.org/vert_72) was used to predict the binding sites between SIRT1 mRNA and miR-494. A total of 354 transcripts containing 371 sites were predicted. The target gene SIRT1 was selected due to its important role in myocardial I/R injury (30). The wild-type (WT) 3'-UTR sequence of SIRT1 that can bind to miR-494 or the mutant (MUT) 3'-UTR sequence was amplified and then cloned into a pGL3 vector (Promega

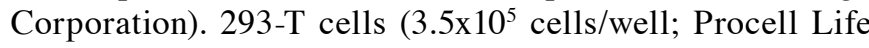
Science \& Technology Co., Ltd.) were co-transfected with WT SIRT1 3'UTR or MUT SIRT1 3'-UTR (0.5 $\mu \mathrm{g})$ and miR-494 inhibitor, miR-494 mimic or the corresponding NCs $(50 \mathrm{nM})$ using Lipofectamine 2000. At 24 h post-transfection, the dual luciferase reporter gene assay kit (Promega Corporation) was used to measure luciferase activities according to the manufacturer's protocol. Luciferase activity was normalized to Renilla luciferase.

Statistical analysis. Data are presented as the mean \pm SD. All experiments were performed in triplicate. Comparisons among multiple groups were analyzed using one-way ANOVA followed by a Tukey's post hoc test. Statistical analyses were performed using SPSS software (version 22.0; IBM Corp.). $\mathrm{P}<0.05$ was considered to indicate a statistically significant difference.

\section{Results}

Effects of miR-494 on H/R-induced cardiomyocyte injury. Following $12 \mathrm{~h}$ hypoxia and $3 \mathrm{~h}$ reoxygenation in $\mathrm{H} 9 \mathrm{c} 2$ cells, the expression levels of miR-494 were measured to identify the role of miR-494 in myocardial H/R injury. The RT-qPCR results demonstrated that miR-494 expression levels were significantly downregulated in H/R-treated H9c2 cells compared with control cells. miR-494 mimic, miR-494 inhibitor and the corresponding NCs were transfected into H9c2 cells. The RT-qPCR results demonstrated that miR-494 expression was significantly increased in the miR-494 mimic group compared with the mimic NC group, and significantly decreased in the miR-494 inhibitor group compared with inhibitor NC groups (Fig. 1B). The CCK-8 assay results indicated that, compared with the control group, the percentage of viable cells was significantly reduced in the H/R group. Compared with the corresponding NC groups, cell viability was significantly increased in the miR-494 mimic group, but significantly decreased in the miR-494 inhibitor group (Fig. 1C). Compared with the control group, cells exposed to H/R displayed significantly elevated LDH release, but significantly decreased SOD activity (Fig. 1D and E). In H/R-exposed cells transfected with miR-494 mimic, LDH levels were significantly decreased and SOD activity was significantly increased compared with the mimic NC group. miR-494 inhibitor significantly increased LDH release and reduced SOD activity following H/R stimulation compared with the inhibitor NC group.

Effects of miR-494 on H/R-induced cardiomyocyte apoptosis and autophagy. In $\mathrm{H} 9 \mathrm{c} 2$ cells treated with $\mathrm{H} / \mathrm{R}$, the rate of apoptosis was significantly higher compared with the control group (Fig. 2A). Moreover, in H/R-exposed cells, compared with the mimic NC group, the miR-494 mimic group displayed a significantly lower rate of apoptosis, whereas the miR-494 inhibitor group displayed a significantly higher rate of apoptosis compared with the inhibitor NC group.

Similar to the flow cytometry results, the morphological alterations of $\mathrm{H} 9 \mathrm{c} 2$ cells indicated by TUNEL staining suggested that H/R significantly increased apoptosis compared with the control group. DNA fragmentation and nuclear condensation are unique morphological features of cell apoptosis following $\mathrm{H} / \mathrm{R}$ treatment (31). Moreover, following $\mathrm{H} / \mathrm{R}$ treatment, the miR-494 mimic group displayed a significantly decreased number of cells with nuclear staining compared with the mimic NC group, whereas the miR-494 inhibitor group 

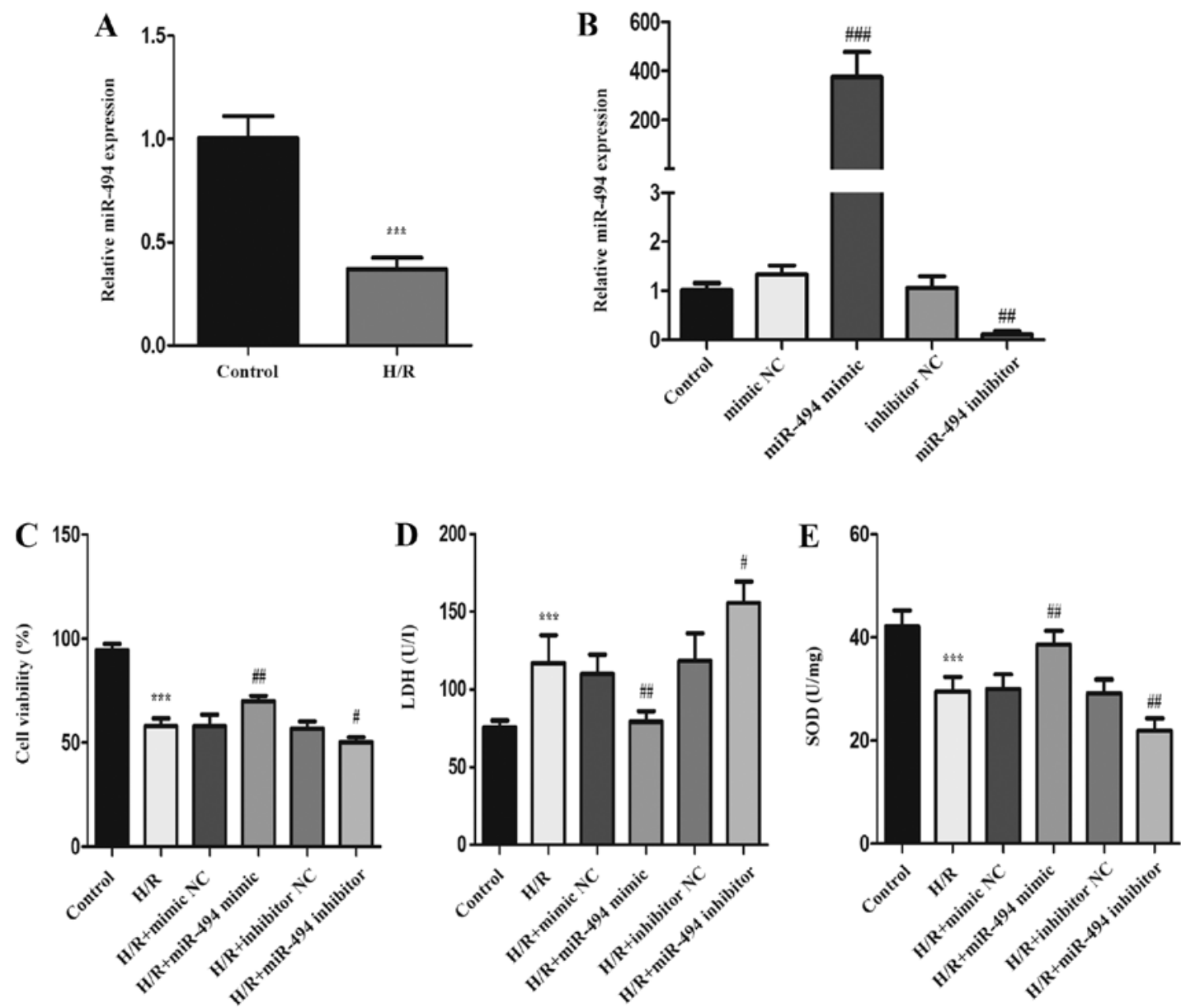

Figure 1. Effects of miR-494 on H/R-induced injury in H9c2 cells. (A) miR-494 expression levels following (A) H/R injury and (B) transfection with miR-494 mimic, miR-494 inhibitor and the corresponding NCs were determined via reverse transcription-quantitative PCR. (C) Cell viability was assessed by performing a Cell Counting Kit-8 assay. (D) LDH release was detected using an LDH cytotoxicity assay. (E) SOD activity was detected using a SOD assay kit. Data are presented as the mean $\pm \mathrm{SD}(\mathrm{n}=3) .{ }^{* * *} \mathrm{P}<0.001$ vs. control; ${ }^{\#} \mathrm{P}<0.05,{ }^{\# \#} \mathrm{P}<0.01$ and ${ }^{\# \# \#} \mathrm{P}<0.001$ vs. corresponding NC group. miR, microRNA; H/R, hypoxia/reperfusion; NC, negative control; $\mathrm{LDH}$, lactate dehydrogenase; SOD, superoxide dismutase.

displayed a significantly increased number of TUNEL-positive cells compared with the inhibitor NC group (Fig. 2B).

Western blotting was performed to detect the expression levels of two apoptosis-related proteins, $\mathrm{Bcl}-2$ and $\mathrm{Bax}$. The H/R group displayed significantly decreased Bcl-2 expression levels and increased Bax expression levels compared with the control group. H/R-mediated effects on apoptosis-related protein expression levels were further enhanced in the miR-494 inhibitor group, whereas miR-494 mimic partially reversed H/R-induced alterations to apoptosis-related protein expression (Fig. 3A). Subsequently, the effects of miR-494 on H/R-induced cell autophagy were evaluated. The expression levels of autophagy-related proteins $\mathrm{p} 62$ and Beclin-1, as well as the ratio of LC3BII/LC3BI were detected via western blotting (Fig. 3B). The results suggested that H/R stimulation activated autophagy, which was demonstrated by a significant increase in Beclin-1 protein expression levels and the ratio of LC3BII/LC3BI, and a significant decrease in p62 protein expression levels in the H/R group compared with the control group. However, miR-494 mimic significantly decreased the expression levels of Beclin-1 and the ratio of LC3BII/LC3BI, but elevated 02 protein expression levels in $\mathrm{H} / \mathrm{R}$-treated cells compared with the mimic $\mathrm{NC}$ group. miR-494 inhibitor resulted in the opposite effects on cell autophagy following $\mathrm{H} / \mathrm{R}$ stimulation.
The present study further assessed the phosphorylation of PI3K, AKT and mTOR following H/R injury combined with miR-494 inhibitor or mimic transfection to investigate whether miR-494 regulated the PI3K/AKT/mTOR signaling pathway in H/R-induced apoptosis and autophagy in H9c2 cells. The western blotting results suggested that $H / R$ stimulation decreased PI3K, AKT and mTOR phosphorylation, and significantly decreased the ratios of $\mathrm{p}-\mathrm{PI} 3 \mathrm{~K} / \mathrm{PI} 3 \mathrm{~K}$, p-AKT/AKT and p-mTOR/mTOR compared with the control group. However, in H/R-treated cells, compared with the mimic NC group, miR-494 mimic markedly enhanced the expression levels of p-PI3K, p-AKT and p-mTOR, whereas miR-494 inhibitor markedly decreased the expression levels of p-PI3K, p-AKT and p-mTOR levels compared with the inhibitor NC group (Fig. 3C).

SIRT1 is a target gene of miR-494. TargetScan was used to predict the potential target genes of miR-494. The prediction results demonstrated that the 3'-UTR of SIRT1 had a 7-nucleotide seed sequence complementary to miR-494 (Fig. 4A). Compared with mimic NC, miR-494 mimic significantly reduced the luciferase activity of WT SIRT1 3'-UTR in 293-T cells. However, the luciferase activity of MUT SIRT1 3'-UTR was not significantly altered by miR-494 mimic compared with 

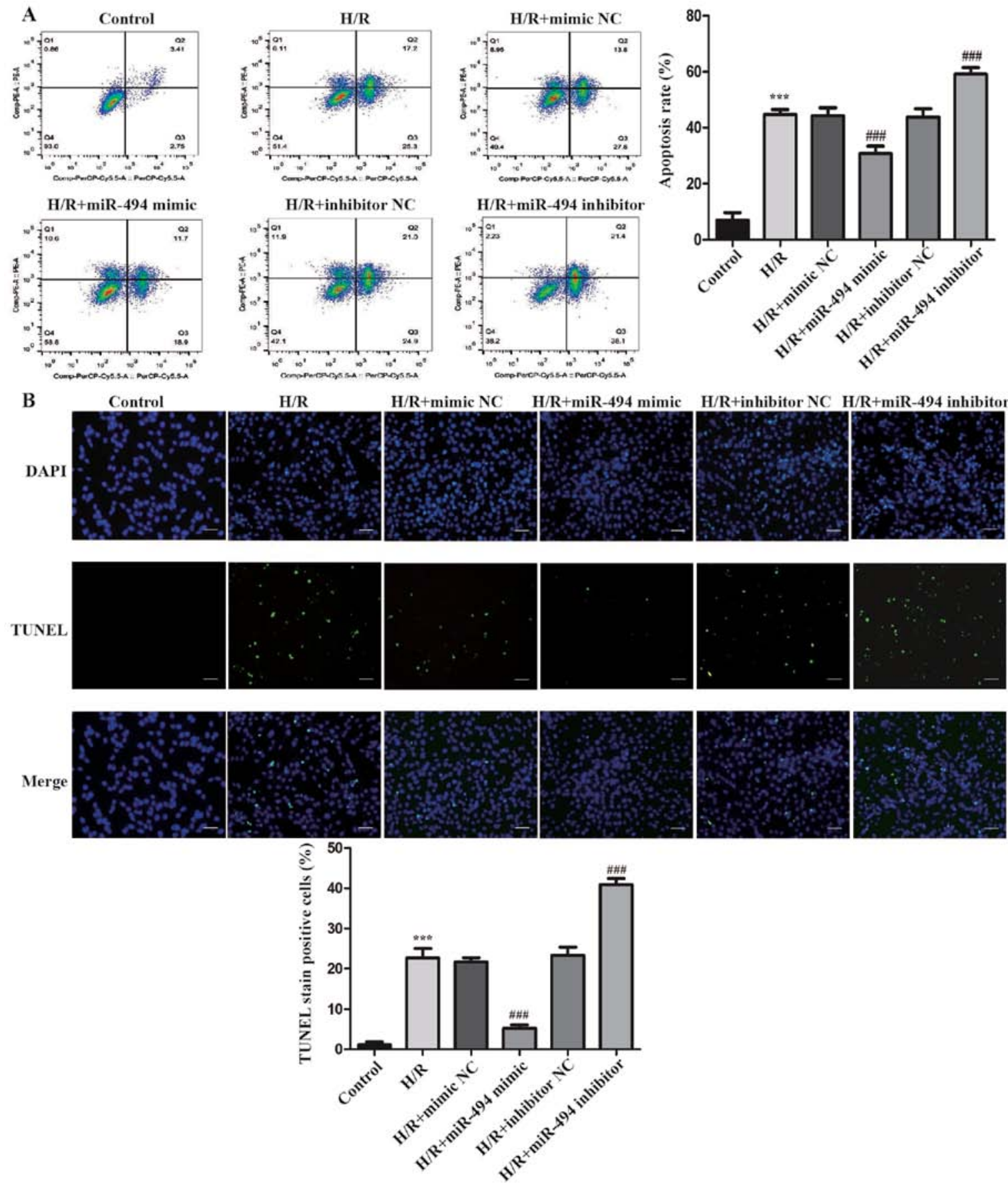

Figure 2. miR-494 regulates H9c2 cell apoptosis and autophagy following H/R treatment. (A) Cell apoptosis was detected by performing Annexin V-PE/7-Ami no-Actinomycin D double staining. (B) TUNEL immunofluorescence staining was performed to detect apoptosis-positive cells (scale bar, $50 \mu \mathrm{m}$ ). Data are presented as the mean $\pm \mathrm{SD}(\mathrm{n}=3) .{ }^{* * *} \mathrm{P}<0.001$ vs. control; ${ }^{\# \# *} \mathrm{P}<0.001$ vs. corresponding $\mathrm{NC}$ group. miR, microRNA; H/R, hypoxia/reperfusion; NC, negative control.

mimic NC. Following transfection with miR-494 inhibitor, the luciferase activity of WT SIRT1 3'-UTR was significantly increased compared with the inhibitor NC group. Similarly to miR-494 mimic, miR-494 inhibitor did not significantly alter the luciferase activity of MUT SIRT1 3'-UTR compared with inhibitor NC (Fig. 4B). Subsequently, the western blotting results demonstrated that SIRT1 expression in H/R-induced H9c2 cells was significantly higher compared with control cells (Fig. 4C). To further confirm the interaction between miR-494 and SIRT1, RT-qPCR and western blotting were performed to detect the mRNA and protein expression levels of SIRT1, respectively. miR-494 mimic significantly decreased
SIRT1 mRNA and protein expression levels compared with the mimic NC group, whereas miR-494 inhibitor displayed the opposite effect compared with the inhibitor NC group (Fig. 4D and E).

SIRT1 regulates $H / R$-induced injury in $H 9 c 2$ cells. siSIRT1 was used to knock down SIRT1 expression in H9c2 cells to investigate the involvement of SIRT1 in the pathogenesis of H/R-induced injury (Fig. 5A and B). Compared with the siNC group, the mRNA and protein expression levels of SIRT1 were significantly downregulated following siSIRT1 transfection. LDH release, cell viability and SOD activity levels were 
A

A

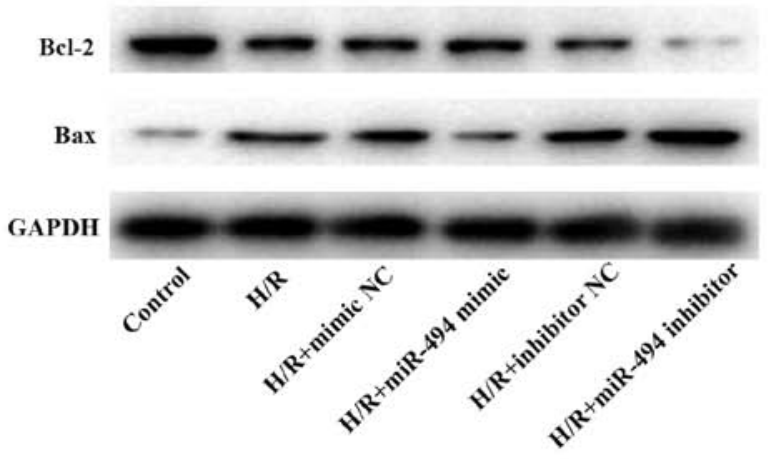

B LC3B I

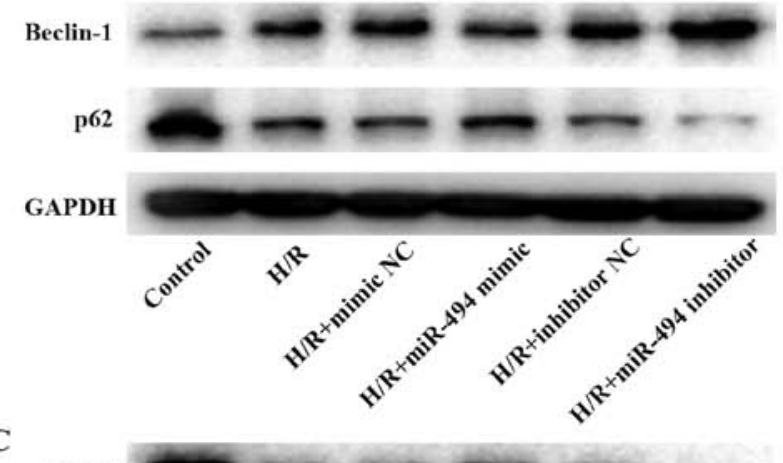

C

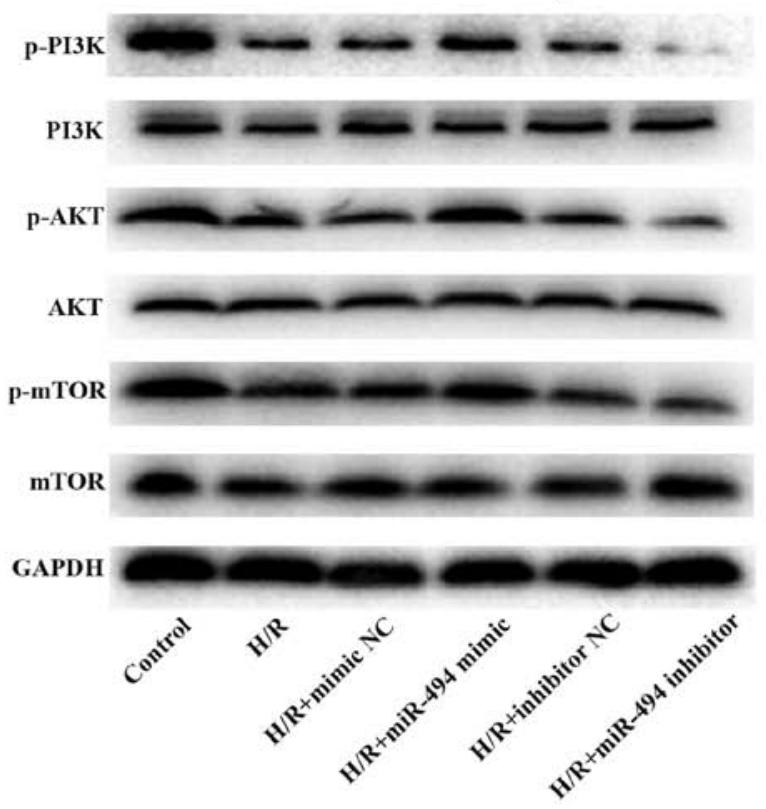

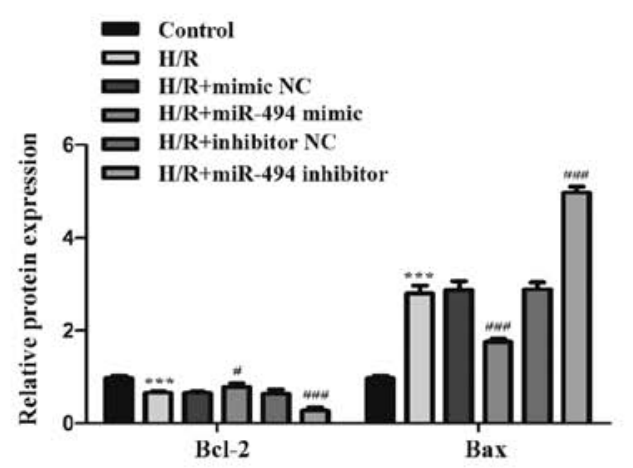
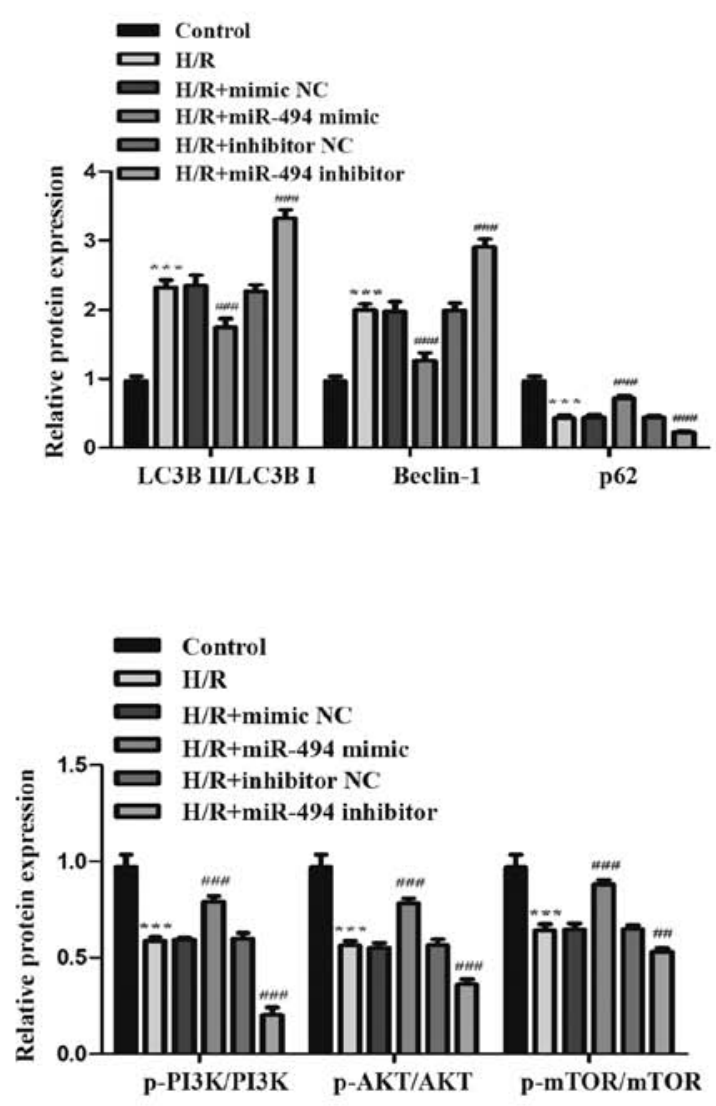

Figure 3. miR-494 regulates cell apoptosis and autophagy via the PI3K/AKT/mTOR signaling pathway. Western blotting was performed to measure the expression levels of (A) apoptosis- (B) autophagy- and (C) PI3K/AKT/mTOR signaling pathway-related proteins in H/R-treated H9c2 cells following transfection with miR-494 mimic, miR-494 inhibitor and the corresponding NCs. Data are presented as the mean $\pm \mathrm{SD}(\mathrm{n}=3){ }^{* * *} \mathrm{P}<0.001$ vs. control; ${ }^{*} \mathrm{P}<0.05$, ${ }^{\# \#} \mathrm{P}<0.01$ and

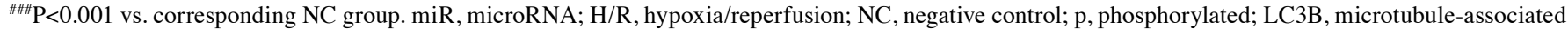
proteins 1A/1B light chain $3 \mathrm{~b} 2$.

detected in H/R-treated H9c2 cells following co-transfection with siSIRT1 and miR-494 inhibitor. siSIRT1 significantly reduced $\mathrm{H} / \mathrm{R}$ injury, as demonstrated by inhibition of LDH activity, and increased SOD activity and cell viability in the co-transfection group compared with the miR-494 inhibitor group (Fig. 5C-E).

miR-494 regulates $H / R$-induced cardiomyocyte apoptosis and autophagy via modulating SIRT1 expression. The effects of SIRT1 on apoptosis and autophagy were further examined to investigate whether miR-494 served a role in H/R-induced cardiomyocyte injury via regulating SIRT1.

The flow cytometry assay results demonstrated that, compared with the miR-494 inhibitor and siNC co-transfection group, the apoptosis rate of H/R-treated cells was significantly decreased in the miR-494 inhibitor and siSIRT1 co-transfection group (Fig. 6A).

The results of the TUNEL staining assay indicated that the ratio of TUNEL-positive cells was significantly increased in $\mathrm{H} / \mathrm{R}$-treated cells in the miR-494 inhibitor group compared 
A

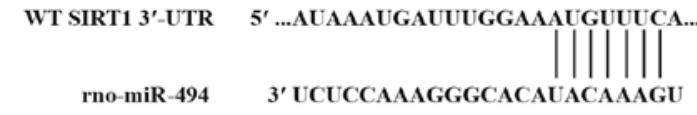

MUT SIRT1 3'-UTR $\quad 5$ '...AUAAAUGAUUUGGAAUACAAAGA...
C

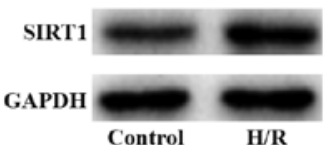

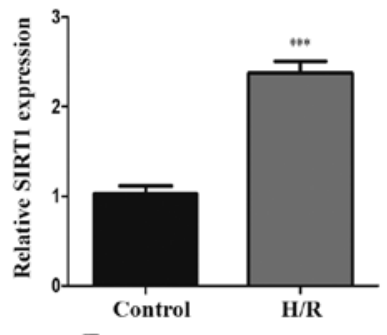

$\mathbf{E}$
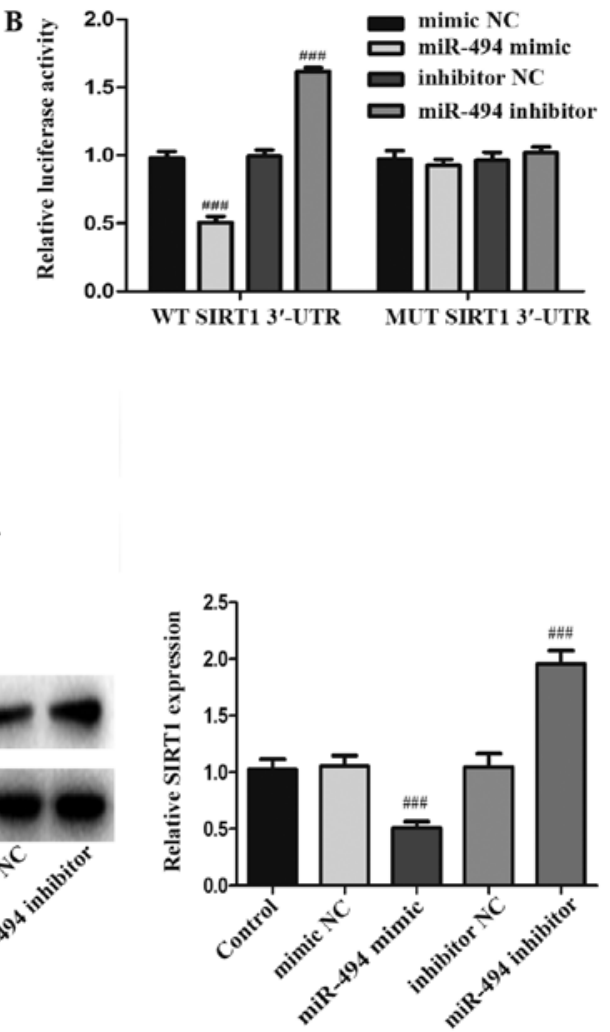

Figure 4. miR-494 targets SIRT1. (A) The binding sites between miR-494 and SIRT1 3'-UTR were predicted using TargetScan. (B) The luciferase reporter assay was performed to evaluate the interaction between miR-494 and SIRT1. (C) SIRT1 protein expression levels following H/R injury were measured via western blotting. SIRT1 (D) mRNA and (E) protein expression levels in H9c2 cells following transfection with miR-494 mimic, miR-494 inhibitor and the corresponding NCs were measured via reverse transcription-quantitative PCR and western blotting, respectively. Data are presented as the mean \pm SD ( $\mathrm{n}=3$ ). ${ }^{* * *} \mathrm{P}<0.001$ vs. control; ${ }^{\# \# \#} \mathrm{P}<0.001$ vs. corresponding NC group. miR, microRNA; SIRT1, silent information regulator 1; 3'-UTR, 3'-untranslated region; $\mathrm{H} / \mathrm{R}$, hypoxia/reperfusion; NC, negative control; WT, wild-type; MUT, mutant.
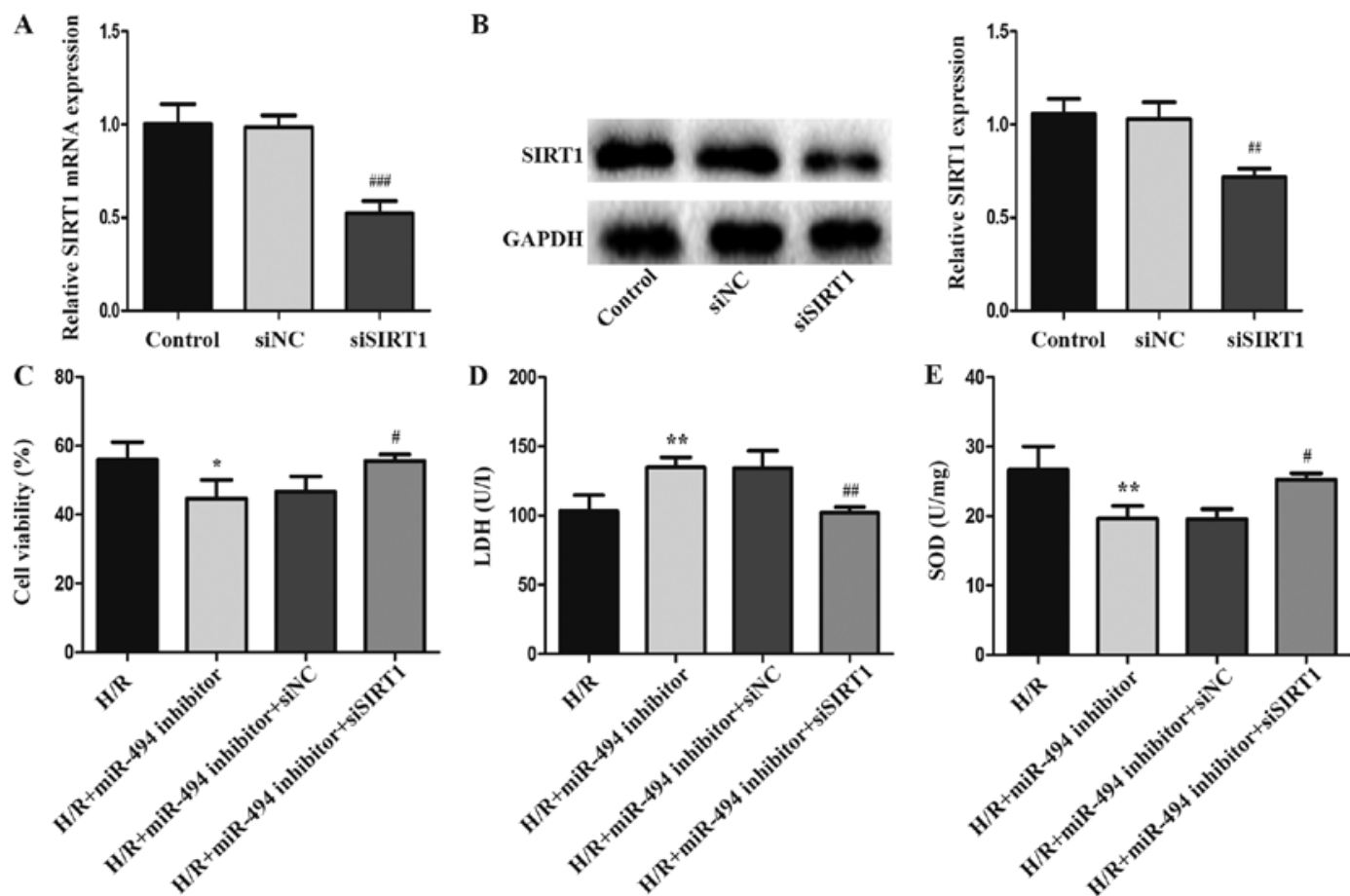

Figure 5. miR-494 regulates myocardial H/R injury via modulating SIRT1 expression. SIRT1 (A) mRNA and (B) protein expression levels in H/R-treated H9c2 cells following transfection with siNC or siSIRT1 were measured via reverse transcription-quantitative PCR and western blotting, respectively. (C) Cell viability was assessed by performing a Cell Counting Kit-8 assay. (D) LDH release was detected using an LDH cytotoxicity assay. (E) SOD activity was detected using a SOD assay kit. Data are presented as the mean $\pm \mathrm{SD}(\mathrm{n}=3) .{ }^{*} \mathrm{P}<0.05$ and ${ }^{* *} \mathrm{P}<0.01 \mathrm{vs}$. H/R; ${ }^{\#} \mathrm{P}<0.05,{ }^{\# \#} \mathrm{P}<0.01$ and ${ }^{\# \# \#} \mathrm{P}<0.001 \mathrm{vs}$. siNC or H/R + miR-494 inhibitor + siNC. miR, microRNA; H/R, hypoxia/reperfusion; SIRT1, silent information regulator 1; si, small interfering RNA; NC, negative control; LDH, lactate dehydrogenase; SOD, superoxide dismutase. 
A
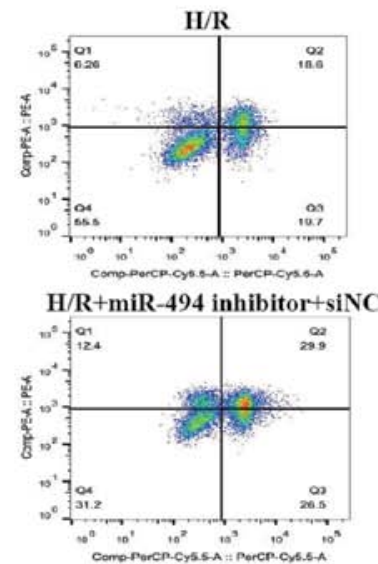

B

DAPI

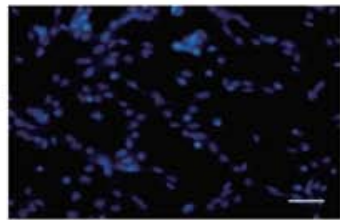

TUNEL
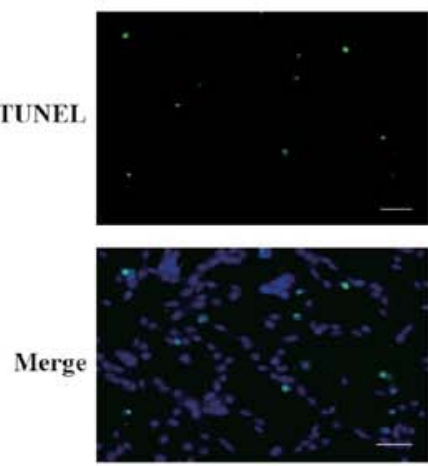

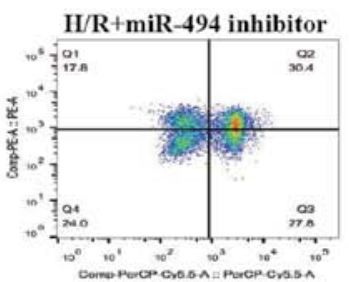

H/R+miR-494 inhibitor+siSIRT1

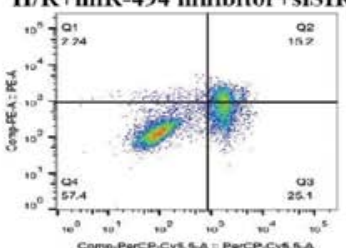

$\mathrm{H} / \mathrm{R}+\mathrm{miR}-494$ inhibitor
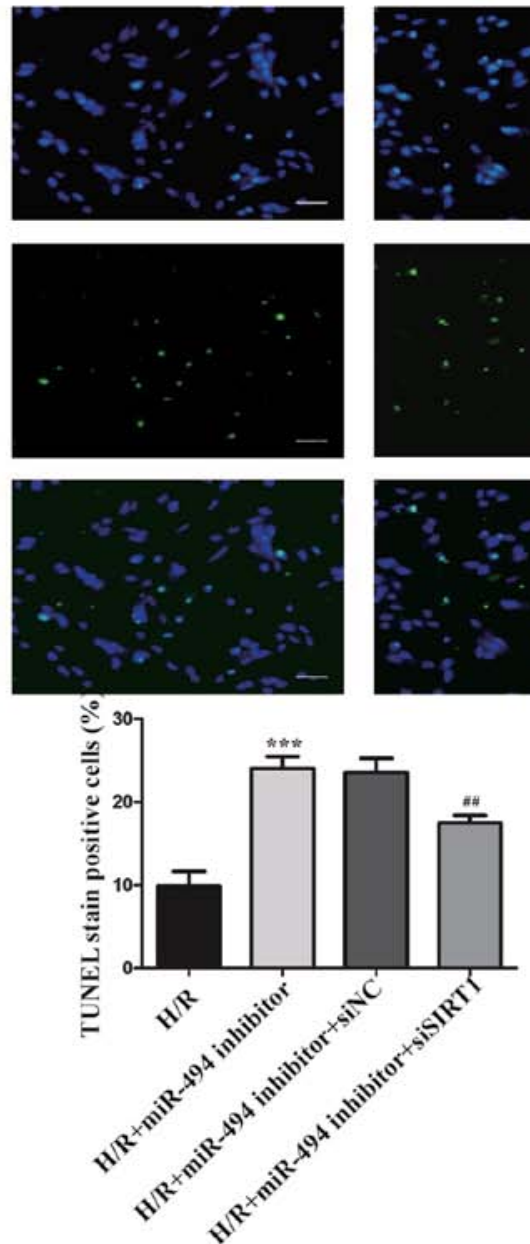

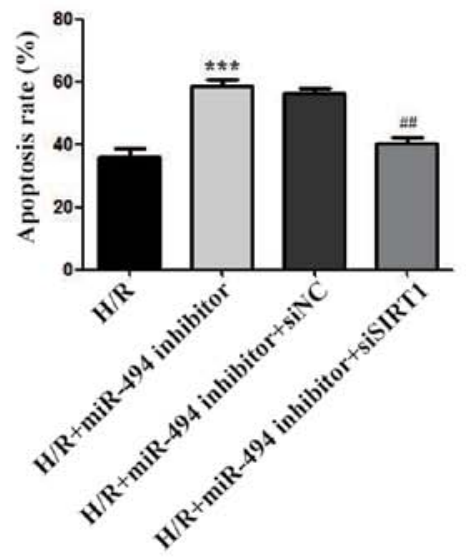

H/R+miR-494 inhibitor+siNC $\quad H / R+m i R-494$ inhibitor+siSIRT1
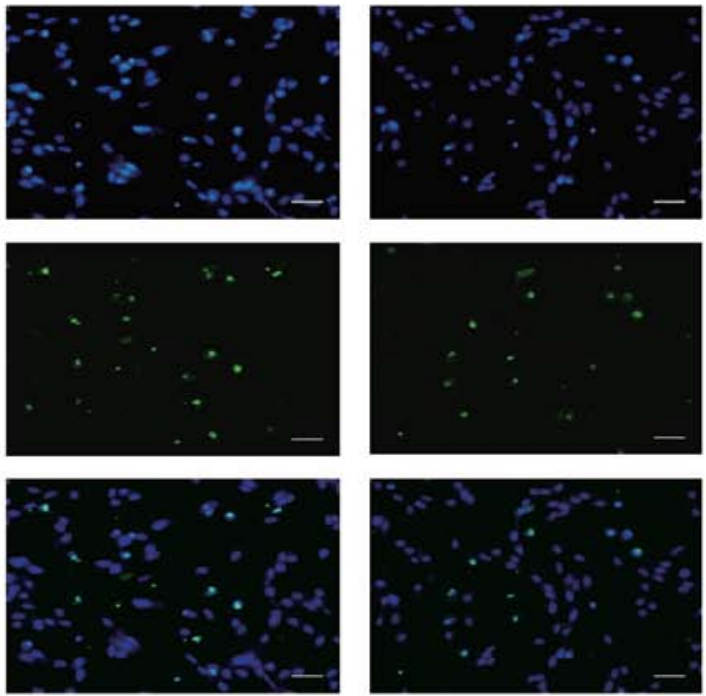

Figure 6. Effects of SIRT1 interference on cell apoptosis and autophagy in H/R-induced H9c2 cells. (A) Cell apoptosis was detected by performing Annexin V-PE/ 7-Amino-Actinomycin D double staining. (B) TUNEL immunofluorescence staining was performed to detect apoptosis-positive cells (scale bar, $50 \mu \mathrm{m}$ ). Data are presented as the mean $\pm \mathrm{SD}(\mathrm{n}=3){ }^{* * *} \mathrm{P}<0.001$ vs. $\mathrm{H} / \mathrm{R} ;{ }^{* \# *} \mathrm{P}<0.01 \mathrm{vs.} \mathrm{H} / \mathrm{R}+\mathrm{miR}-494$ inhibitor + siNC. SIRT1, silent information regulator $1 ; \mathrm{H} / \mathrm{R}$, hypoxia/reperfusion; siNC, small interfering RNA negative control.

with the H/R group, an effect that was partially reversed by co-transfection with siSIRT1 transfection (Fig. 6B).

The levels of apoptosis- and autophagy-related proteins were detected via western blotting. The results suggested that siSIRT1 co-transfection attenuated H/R-induced H9c2 cell apoptosis and autophagy compared with the miR-494 inhibitor and siNC co-transfection group. Compared with miR-494 inhibitor transfection alone, co-transfection with siSIRT1 significantly reduced cell apoptosis in H/R-treated cells, as evidence by decreased Bax expression levels and increased Bcl-2 expression levels (Fig. 7A). Concurrently, in H/R-treated cells, siSIRT1 co-transfection significantly decreased Beclin-1 expression levels and the ratio of LC3BII/LC3BI, but increased p62 expression levels compared with the miR-494 inhibitor group (Fig. 7B).

miR-494 mediates effects on $H / R$-induced cardiomyocyte apoptosis and autophagy via PI3K/AKT/mTOR signaling. $\mathrm{PI} 3 \mathrm{~K} / \mathrm{AKT} / \mathrm{mTOR}$ is a crucial signaling pathway that 
A

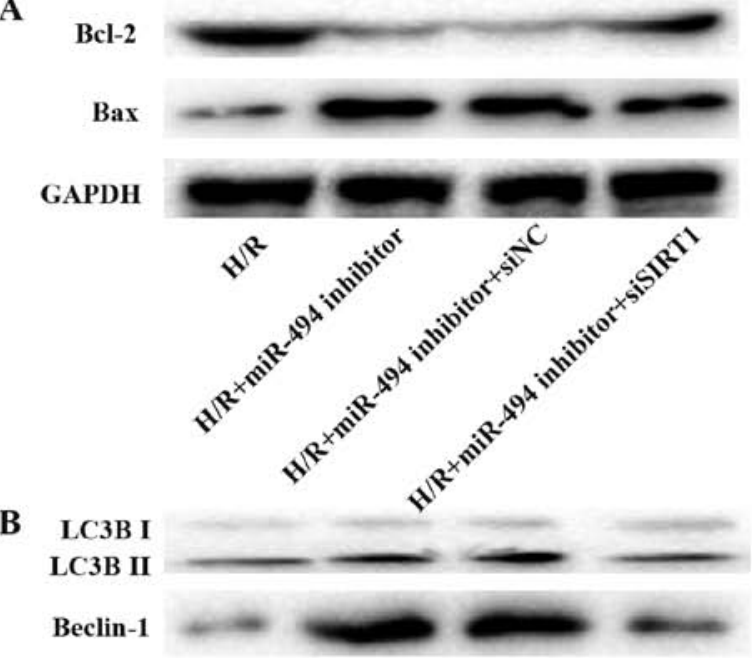

p62

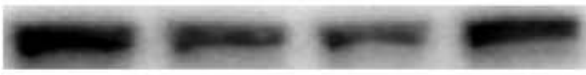

GAPDH
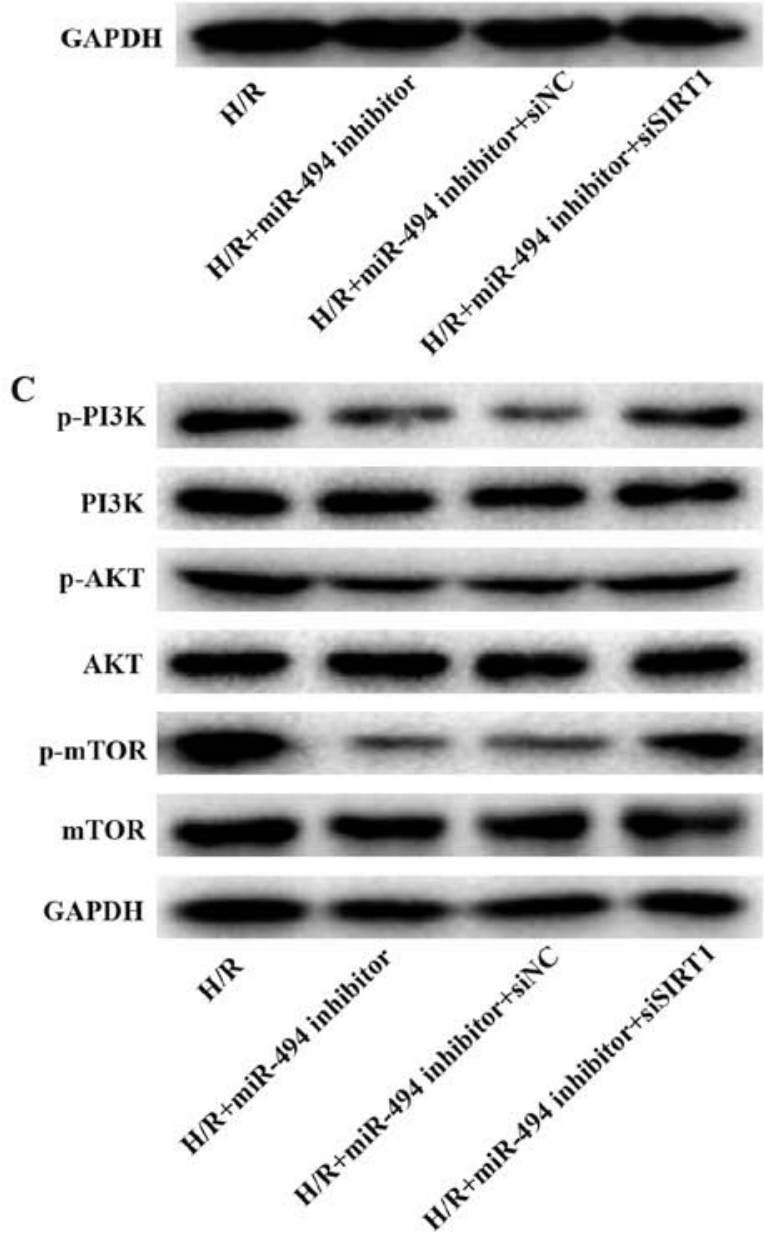
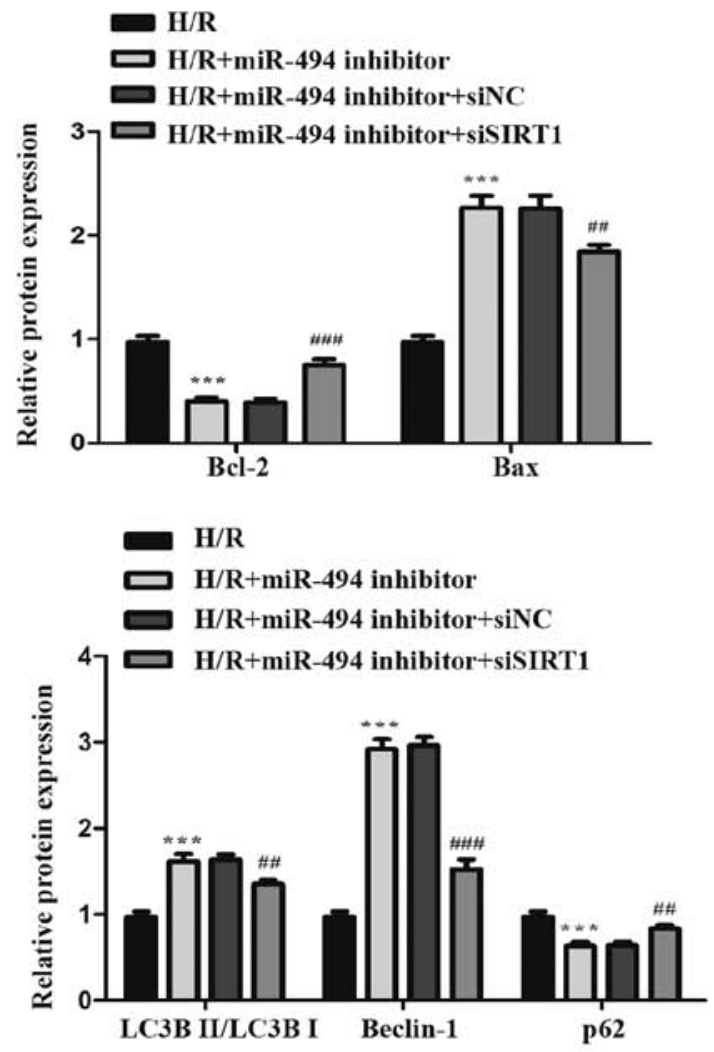

Figure 7. miR-494 directly targets SIRT1 to regulate the activation of the PI3K/AKT/mTOR signaling pathway. Western blotting was performed to detect the expression levels of (A) apoptosis-, (B) autophagy- and (C) PI3K/AKT/mTOR signaling pathway-related proteins in H/R-treated H9c2 cells following transfection with miR-494 inhibitor, siNC or siSIRT1. Data are presented as the mean $\pm \mathrm{SD}(\mathrm{n}=3)$. ${ }^{* * *} \mathrm{P}<0.001 \mathrm{vs}$. H/R; ${ }^{\# \#} \mathrm{P}<0.01$ and ${ }^{\# \# \#} \mathrm{P}<0.001$ vs. H/R + miR-494 inhibitor + siNC. miR, microRNA; SIRT1, silent information regulator 1; H/R, hypoxia/reperfusion; si, small interfering RNA; NC, negative control; p, phosphorylated; LC3B, microtubule-associated proteins 1A/1B light chain $3 \mathrm{~b} 2$.

serves a key role in cardiac protection (32). The expression levels of p-PI3K, p-AKT and p-mTOR were detected to further assess whether miR-494 regulated the activation of the PI3K/AKT/mTOR signaling pathway by directly targeting SIRT1. miR-494 inhibitor significantly decreased the expression levels of p-PI3K, p-AKT and p-mTOR in H/R-treated cells. Moreover, the expression levels of p-PI3K, p-AKT and p-mTOR were significantly increased in H/R-treated cells following co-transfection with siSIRT1 compared with miR-494 inhibitor transfection alone (Fig. 7C). 


\section{Discussion}

Myocardial I/R injury has been associated with cardiomyocyte death and remodeling, which can lead to adverse cardiovascular outcomes, such as heart failure and death (33). During the pathological process of myocardial I/R injury, autophagy and apoptosis can interact and participate in the process (34). The present study suggested that miR-494 attenuated cell injury following $\mathrm{H} / \mathrm{R}$ treatment by inhibiting apoptosis and autophagy in H9c2 cells. Moreover, miR-494 regulated activation of the PI3K/AKT/mTOR signaling pathway by directly targeting SIRT1.

Cardiomyocyte apoptosis exerts key effects on myocardial I/R injury (35). In addition, an increasing number of studies have suggested that low level autophagy activation serves a protective role in I/R injury by providing free amino acids and nucleotides, and clearing damaged organelles $(36,37)$. However, excessive autophagy contributes to over self-digestion and degradation of numerous cellular components, which further aggravates myocardial I/R injury (38). The present study indicated that apoptosis and autophagy were significantly increased in H/R-treated H9c2 cells compared with control cells, which further suggested that $H / R$ treatment could aggravate myocardial I/R injury. Moreover, the present study indicated that apoptosis and autophagy exerted negative effects on $\mathrm{H} 9 \mathrm{c} 2$ cells during $\mathrm{H} / \mathrm{R}$ injury. A number of miRs, such as miR-1, miR-195 and miR-320, could regulate numerous signaling molecules to reduce the risk of myocardial apoptosis and autophagy (39-41). In the present study, significantly decreased expression levels of miR-494 were detected in H/R-treated $\mathrm{H} 9 \mathrm{c} 2$ cells compared with control cells, which was similar to a previous study that reported that miR-494 was associated with I/R-induced cardiac injury (20). In addition, miR-494 overexpression decreased LDH release and apoptosis rates, but increased SOD activity levels and cell viability in $\mathrm{H} / \mathrm{R}$-treated $\mathrm{H} 9 \mathrm{c} 2$ cells compared with mimic $\mathrm{NC}$. Furthermore, miR-494 overexpression decreased the expression levels of Beclin-1 and the ratio of LC3BII/LC3BI, but increased the ratio of $\mathrm{Bcl}-2 / \mathrm{Bax}$ and the expression levels of p62 in H/R-treated H9c2 cells compared with inhibitor NC. By contrast, miR-494 knockdown displayed the opposite effects on $\mathrm{H} / \mathrm{R}$-treated $\mathrm{H} 9 \mathrm{c} 2$ cells. Therefore, the results suggested that miR-494 overexpression reduced H/R-induced cell apoptosis and autophagy, indicating that miR-494 may serve a protective role against myocardial I/R injury.

miRs function by degrading or inhibiting the translation of target mRNAs (42). The present study predicted and identified the target gene of miR-494. Previous studies reported that miR-494 could target and negatively regulate SIRT1 expression $(43,44)$. As an essential member of the seven categories of the sirtuin protein family, SIRT1 is considered as a critical regulator of cell apoptosis and autophagy (45). Recently, numerous studies reported that SIRT1 was involved in myocardial I/R injury $(46,47)$. Ding et al (48) demonstrated that miR-29a inhibition could activate SIRT1, thus preventing I/R injury by inhibiting oxidative stress. Hsu et al (49) reported that SIRT1 attenuated oxidative stress and inhibited apoptosis by upregulating cardioprotective molecules and downregulating proapoptotic molecules during I/R. The present study indicated that SIRT1 was a target gene of miR-494 using online tools and performing luciferase reporter assays. The results demonstrated that miR-494 overexpression decreased SIRT1 expression levels compared with mimic NC. Following co-transfection with siSIRT1 and miR-494 inhibitor, the aggravating effects of miR-494 inhibitor on H/R-induced $\mathrm{H} 9 \mathrm{c} 2$ cell apoptosis and autophagy were partially reversed. Therefore, the results indicated that the effects of miR-494 on autophagy and apoptosis were mediated via SIRT1.

As a significant intracellular signaling pathway, the $\mathrm{PI} 3 \mathrm{~K} / \mathrm{AKT} / \mathrm{mTOR}$ signaling pathway is involved in the regulation of multiple biological processes, including apoptosis, inflammation and innate immunity (50). Additionally, the PI3K/AKT/mTOR signaling pathway can regulate myocardial I/R injury-induced effects $(51,52)$. Moreover, a previous study indicated that SIRT1 was involved in regulating the activation of the PI3K/AKT/mTOR signaling pathway and protecting cells against apoptosis (53). Zhang et al (54) also reported that SIRT1 was involved in regulating cell cycle arrest via the PI3K/AKT/mTOR signaling pathway. The present study demonstrated that, compared with inhibitor NC, miR-494 inhibitor transfection inhibited the $\mathrm{PI} 3 \mathrm{~K} / \mathrm{AKT} / \mathrm{mTOR}$ signaling pathway in H/R-treated H9c2 cells, which was significantly reversed by siSIRT1 transfection. Collectively, the results suggested that miR-494 could signal via the SIRT1/PI3K/AKT/mTOR axis to inhibit H9c2 cell apoptosis and autophagy during H/R injury. However, a rat model should be established to verify the results of the present study.

In conclusion, the present study indicated that miR-494 targeted SIRT1 to regulate the PI3K/AKT/mTOR signaling pathway, which alleviated cell apoptosis and autophagy, thereby protecting cardiomyocytes against I/R injury.

\section{Acknowledgements}

Not applicable.

\section{Funding}

The present study was supported by the National Natural Science Foundation of China (grant no. U1404833) and the Joint Construction Project of Medical Science and Technology Research Plan of Henan Province (grant no. LHGJ20191110).

\section{Availability of data and materials}

The datasets used and/or analyzed during the current study are available from the corresponding author on reasonable request.

\section{Authors' contributions}

$\mathrm{XM}, \mathrm{YY}$ and SN conceived and designed the study. DF, KW, $\mathrm{LH}$ and JZ performed the experiments and collected the data. $\mathrm{SN}, \mathrm{ZL}, \mathrm{ZJ}$ and QW analyzed and interpreted the data. SN performed the experiments and drafted the manuscript. All authors read and approved the final manuscript.

\section{Ethics approval and consent to participate}

Not applicable. 


\section{Patient consent for publication}

Not applicable.

\section{Competing interests}

The authors declare that they have no competing interests.

\section{References}

1. Gupta R and Wood DA: Primary prevention of ischaemic heart disease: Populations, individuals, and health professionals. Lancet 394: 685-696, 2019.

2. Nelson T, Garg P, Clayton RH and Lee J: The role of cardiac MRI in the management of ventricular arrhythmias in ischaemic and non-ischaemic dilated cardiomyopathy. Arrhythm Electrophysiol Rev 8: 191-201, 2019.

3. Hausenloy DJ and Yellon DM: Myocardial ischemia-reperfusion injury: A neglected therapeutic target. J Clin Invest 123: 92-100, 2013.

4. Rader DJ: Lysosomal acid lipase deficiency - A new therapy for a genetic lipid disease. N Engl J Med 373: 1071-1073, 2015.

5. Kaczanowski S: Apoptosis: Its origin, history, maintenance and the medical implications for cancer and aging. Phys Biol 13 031001,2016

6. Khalil H,AbdElHady A,Elawdan KA, Mohamed D, Mohamed DD Abd El Maksoud AI, El-Chennawi FA, El-Fikiy B and El-Sayed IH: The mechanical autophagy as a part of cellular immunity; facts and features in treating the medical disorders. Immunol Invest: Sep 29 , 2020 (Epub ahead of print). doi: 10.1080/08820139.2020.1828453.

7. Dong Y, Chen H, Gao J, Liu Y, Li J and Wang J: Molecular machinery and interplay of apoptosis and autophagy in coronary heart disease. J Mol Cell Cardiol 136: 27-41, 2019.

8. Wang A, Zhang H, Liang Z, Xu K, Qiu W, Tian Y, Guo H, Jia J, Xing $\mathrm{E}$, Chen R, et al: U0126 attenuates ischemia/reperfusion-induced apoptosis and autophagy in myocardium through MEK/ERK/ EGR-1 pathway. Eur J Pharmacol 788: 280-285, 2016.

9. Sun MH, Chen XC, Han M, Yang YN, Gao XM, Ma X, Huang Y, Li XM, Gai MT, Liu F, et al: Cardioprotective effects of constitutively active MEK1 against $\mathrm{H}_{2} \mathrm{O}_{2}$-induced apoptosis and autophagy in cardiomyocytes via the ERK1/2 signaling pathway. Biochem Biophys Res Commun 512: 125-130, 2019.

10. Yuan H, Mischoulon D, Fava M and Otto MW: Circulating microRNAs as biomarkers for depression: Many candidates, few finalists. J Affect Disord 233: 68-78, 2018.

11. Liu K, Ma L, Zhou F, Yang Y, Hu HB, Wang L and Zhong L: Identification of microRNAs related to myocardial ischemic reperfusion injury. J Cell Physiol 234: 11380-11390, 2019.

12. Huang Z, Wu S, Kong F, Cai X, Ye B, Shan P and Huang W: MicroRNA-21 protects against cardiac hypoxia/reoxygenation injury by inhibiting excessive autophagy in $\mathrm{H} 9 \mathrm{c} 2$ cells via the Akt/mTOR pathway. J Cell Mol Med 21: 467-474, 2017

13. Lu TX and Rothenberg ME: MicroRNA. J Allergy Clin Immunol 141: 1202-1207, 2018.

14. Jin Y and Ni S: miR-496 remedies hypoxia reoxygenation-induced $\mathrm{H} 9 \mathrm{c} 2$ cardiomyocyte apoptosis via Hook3-targeted PI3k/Akt/ mTOR signaling pathway activation. J Cell Biochem 121 698-712, 2020

15. Huang ZQ, Xu W, Wu JL, Lu X and Chen XM: MicroRNA-374a protects against myocardial ischemia-reperfusion injury in mice by targeting the MAPK6 pathway. Life Sci 232: 116619, 2019.

16. Tan H, Qi J, Fan BY, Zhang J, Su FF and Wang HT: MicroRNA-24-3p Attenuates myocardial ischemia/reperfusion injury by suppressing RIPK1 expression in mice. Cell Physiol Biochem 51: 46-62, 2018

17. Wu A, Lou L, Zhai J, Zhang D, Chai L, Nie B, Zhu H, Gao Y, Shang $\mathrm{H}$ and Zhao M: miRNA expression profile and effect of wenxin granule in rats with ligation-induced myocardial infarction. Int J Genomics 2017: 2175871, 2017.

18. Zhai F, Zhang X, Guan Y, Yang X, Li Y, Song G and Guan L: Expression profiles of microRNAs after focal cerebral ischemia/ reperfusion injury in rats. Neural Regen Res 7: 917-923, 2012.

19. Sun G, Zhou Y, Li H, Guo Y, Shan J, Xia M, Li Y, Li S, Long D and Feng L: Over-expression of microRNA-494 up-regulates hypoxia-inducible factor-1 alpha expression via PI3K/Akt pathway and protects against hypoxia-induced apoptosis. J Biomed Sci 20 : $100,2013$.
20. Wang X, Zhang X, Ren XP, Chen J, Liu H, Yang J, Medvedovic M, $\mathrm{Hu} \mathrm{Z}$ and Fan GC: MicroRNA-494 targeting both proapoptotic and antiapoptotic proteins protects against ischemia/reperfusion-induced cardiac injury. Circulation 122: 1308-1318, 2010.

21. Meng X, Tan J, Li M, Song S, Miao Y and Zhang Q: Sirt1: Role under the condition of ischemia/hypoxia. Cell Mol Neurobiol 37: $17-28,2017$

22. Yuan Y, Cruzat VF, Newsholme P, Cheng J, Chen Y and Lu Y: Regulation of SIRT1 in aging: Roles in mitochondrial function and biogenesis. Mech Ageing Dev 155: 10-21, 2016.

23. Zhang W, Huang Q, Zeng Z, Wu J, Zhang Y and Chen Z: Sirtl inhibits oxidative stress in vascular endothelial cells. Oxid Med Cell Longev 2017: 7543973, 2017.

24. Han Y, Luo H, Wang H, Cai J and Zhang Y: SIRT1 induces resistance to apoptosis in human granulosa cells by activating the ERK pathway and inhibiting NF-kappaB signaling with anti-inflammatory functions. Apoptosis 22: 1260-1272, 2017.

25. Li Y, Wang P, Yang X, Wang W, Zhang J, He Y, Zhang W, Jing T, Wang B and Lin R: SIRT1 inhibits inflammatory response partly through regulation of NLRP3 inflammasome in vascular endothelial cells. Mol Immunol 77: 148-156, 2016.

26. Liu Y, Li X, Zhu S, Zhang JG, Yang M, Qin Q, Deng SC, Wang B, Tian K, Liu L, et al: Ectopic expression of miR-494 inhibited the proliferation, invasion and chemoresistance of pancreatic cancer by regulating SIRT1 and c-Myc. Gene Ther 22: 729-738, 2015 .

27. Li H, He C, Wang X, Wang H, Nan G and Fang L: MicroRNA-183 affects the development of gastric cancer by regulating autophagy via MALAT1-miR-183-SIRT1 axis and PI3K/AKT/mTOR signals. Artif Cells Nanomed Biotechnol 47: 3163-3171, 2019.

28. Alves-Fernandes DK and Jasiulionis MG: The role of SIRT1 on DNA damage response and epigenetic alterations in cancer. Int J Mol Sci 20: 3153,2019.

29. Livak KJ and Schmittgen TD: Analysis of relative gene expression data using real-time quantitative PCR and the 2(-Delta Delta C(T)) method. Methods 25: 402-408, 2001.

30. Mao GX, Xu XG, Wang SY, Li HF, Zhang J, Zhang ZS, Su HL, Chen SS, Xing WM, Wang YZ, et al: Salidroside delays cellular senescence by stimulating mitochondrial biogenesis partly through a miR-22/SIRT-1 pathway. Oxid Med Cell Longev 2019: 5276096, 2019.

31. Zeyad A, Hamad M, Amor H and Hammadeh ME: Relationships between bacteriospermia, DNA integrity, nuclear protamine alteration, sperm quality and ICSI outcome. Reprod Biol 18: $115-121,2018$.

32. Xu Z, Han X, Ou D, Liu T, Li Z, Jiang G, Liu J and Zhang J: Targeting PI3K/AKT/mTOR-mediated autophagy for tumor therapy. Appl Microbiol Biotechnol 104: 575-587, 2020.

33. Diez ER, Altamirano LB, García IM, Mazzei L, Prado NJ, Fornes MW, Carrión FD, Zumino AZ, Ferder L and Manucha W: Heart remodeling and ischemia-reperfusion arrhythmias linked to myocardial vitamin $d$ receptors deficiency in obstructive nephropathy are reversed by paricalcitol. J Cardiovasc Pharmacol Ther 20: 211-220, 2015.

34. Yao L, Chen H, Wu Q and Xie K: Hydrogen-rich saline alleviates inflammation and apoptosis in myocardial I/R injury via PINK-mediated autophagy. Int J Mol Med 44: 1048-1062, 2019.

35. Majtnerová $P$ and Roušar T: An overview of apoptosis assays detecting DNA fragmentation. Mol Biol Rep 45: 1469-1478, 2018.

36. D'Arcy MS: Cell death: A review of the major forms of apoptosis, necrosis and autophagy. Cell Biol Int 43: 582-592, 2019.

37. Kasprowska-Liśkiewicz D: The cell on the edge of life and death: Crosstalk between autophagy and apoptosis. Postepy Hig Med Dosw 71: 825-841, 2017.

38. Doherty J and Baehrecke EH: Life, death and autophagy. Nat Cell Biol 20: 1110-1117, 2018

39. Zhai C, Tang G, Peng L, Hu H, Qian G, Wang S, Yao J, Zhang X, Fang Y, Yang S, et al: Inhibition of microRNA-1 attenuates hypoxia/re-oxygenation-induced apoptosis of cardiomyocytes by directly targeting Bcl-2 but not GADD45Beta. Am J Transl Res 7: 1952-1962, 2015.

40. Gao CK, Liu H, Cui CJ, Liang ZG, Yao H and Tian Y: Roles of MicroRNA-195 in cardiomyocyte apoptosis induced by myocardial ischemia-reperfusion injury. J Genet 95: 99-108, 2016.

41. Tian ZQ, Jiang H and Lu ZB: MiR-320 regulates cardiomyocyte apoptosis induced by ischemia-reperfusion injury by targeting AKIP1. Cell Mol Biol Lett 23: 41, 2018.

42. Fan ZX and Yang J: The role of microRNAs in regulating myocardial ischemia reperfusion injury. Saudi Med J 36: 787-793, 2015. 
43. Yu X, Zhang S, Zhao D, Zhang X, Xia C, Wang T, Zhang M, Liu T, Huang $\mathrm{W}$ and Wu B: SIRT1 inhibits apoptosis in in vivo and in vitro models of spinal cord injury via microRNA-494. Int J Mol Med 43: 1758-1768, 2019.

44. Tang Q, Len Q, Liu Z and Wang W: Overexpression of miR-22 attenuates oxidative stress injury in diabetic cardiomyopathy via Sirt 1. Cardiovasc Ther Dec 29, 2017 (Epub ahead of print). doi: 10.1111/1755-5922.12318.

45. Luo G, Jian Z, Zhu Y, Zhu Y, Chen B, Ma R, Tang F and Xiao Y: Sirtl promotes autophagy and inhibits apoptosis to protect cardiomyocytes from hypoxic stress. Int J Mol Med 43: 2033-2043, 2019.

46. Potenza MA, Sgarra L, Nacci C, Leo V, De Salvia MA and Montagnani M: Activation of AMPK/SIRT1 axis is required for adiponectin-mediated preconditioning on myocardial ischemiareperfusion (I/R) injury in rats. PLoS One 14: e0210654, 2019.

47. Huang G, Hao F and Hu X: Downregulation of microRNA-155 stimulates sevoflurane-mediated cardioprotection against myocardial ischemia/reperfusion injury by binding to SIRT1 in mice. J Cell Biochem 120: 15494-15505, 2019.

48. Ding S, Liu D, Wang L, Wang G and Zhu Y: Inhibiting MicroRNA-29a protects myocardial ischemia-reperfusion injury by targeting SIRT1 and suppressing oxidative stress and NLRP3-mediated pyroptosis pathway. J Pharmacol Exp Ther 372: 128-135, 2020.

49. Hsu CP, Zhai P, Yamamoto T, Maejima Y, Matsushima S, Hariharan N, Shao D, Takagi H, Oka S and Sadoshima J: Silent information regulator 1 protects the heart from ischemia/reperfusion. Circulation 122: 2170-2182, 2010.
50. McKenna M, McGarrigle S and Pidgeon GP: The next generation of PI3K-Akt-mTOR pathway inhibitors in breast cancer cohorts. Biochim Biophys Acta Rev Cancer 1870: 185-197, 2018.

51. Chi Y, Ma Q, Ding XQ, Qin X, Wang C and Zhang J: Research on protective mechanism of ibuprofen in myocardial ischemia-reperfusion injury in rats through the PI3K/Akt/mTOR signaling pathway. Eur Rev Med Pharmacol Sci 23: 4465-4473, 2019.

52. Li X, Hu X, Wang J, Xu W, Yi C, Ma R and Jiang H: Inhibition of autophagy via activation of $\mathrm{PI} 3 \mathrm{~K} / \mathrm{Akt} / \mathrm{mTOR}$ pathway contributes to the protection of hesperidin against myocardial ischemia/reperfusion injury. Int J Mol Med 42: 1917-1924, 2018.

53. Wang H, Liu H, Chen K, Xiao J, He K, Zhang J and Xiang G: SIRT1 promotes tumorigenesis of hepatocellular carcinoma through PI3K/PTEN/AKT signaling. Oncol Rep 28: 311-318, 2012.

54. Zhang W,Zhang Y, Wang Z,Xu T,Huang C, Yin W, Wang J,Xiong W, Lu W, Zheng $\mathrm{H}$, et al: Tris(2-chloroethyl)phosphate-induced cell growth arrest via attenuation of SIRT1-independent PI3K/Akt/ mTOR pathway. J Appl Toxicol 36: 914-924, 2016.

This work is licensed under a Creative Common Attribution-NonCommercial-NoDerivatives 4.0 International (CC BY-NC-ND 4.0) License. 